\title{
Proceeding
}

Supplementary Issue: Autumn Conferences of Sports Science. Costa Blanca Sports Science Events, 18-19 December 2020. Alicante, Spain.

\section{Improving enjoyment during physical education lesson in primary school students}

\author{
ROSARIA SCHEMBRI ${ }^{1}$, ROBERTO COPPOLA ${ }^{1}$, PATRIZIA TORTELLA², FRANCESCO SGRÒ ${ }^{1}$ \\ ${ }^{1}$ Faculty of Human and Society Sciences, University of Enna "Kore", Enna, Italy \\ ${ }^{2}$ Faculty of Educational Sciences, University of Bolzen, Bolzen, Italy
}

\begin{abstract}
Objective: Assessing the effects of different instructional plans on affective learning aims (i.e., the level of enjoyment) within physical education (PE) classes in elementary school students. Method: The second-grade classes of a primary school were randomly assigned to two different groups (i.e., experimental and control). The control group $(n=29)$ followed the regular physical education curriculum based on skill practices meanwhile the teacher used a directive style. The experimental group $(n=35)$ followed a PE plan based on the use of the Tactical Game Model approach to teach handball-based invasion game. The affective learning aims were assessed by means of the Italian version of the PACES scale and it was administered prior to, and at the end of the instructional period. Scale reliability was estimated for each assessment and group. Furthermore, the impact of the plans was estimated and interpreted according to Cohen's effect size measure. Results: For the control group, the reliability results were between moderate and excellent (i.e., Cronbach's $\alpha$ ranged from 0.82 to 0.93 ), while the same results for experimental group were moderate in pre- and post-training assessment (i.e., Cronbach's $\alpha$ ranged from 0.77 to 0.92 ). No significant betweengroup differences were estimated at the start of the study. At the end of the instructional period there were significant and moderate-to-large differences for the positive scores, while significant and low-to-moderate differences for the negative scores. Implications: Current results identified the TGM approach as an effective strategy for supporting fun and motivational PE lessons, since teachers can use these reflections for developing appropriately PE lessons.
\end{abstract}

Keywords: Tactical game model; PACES; Motor competence; Fun; Elementary school.

\section{Cite this article as:}

Schembri, R., Coppola, R., Tortella, P., \& Sgrò, F. (2021). Improving enjoyment during physical education lesson in primary school students. Journal of Human Sport and Exercise, 16(2proc), S735-S742. doi:https://doi.org/10.14198/jhse.2021.16.Proc2.59

Corresponding author. Faculty of Human and Society Sciences, Laboratory of Performance and Human Movement Analysis, University of Enna "Kore", Cittadella Universitaria, 94100, Enna, Italy.

E-mail: francesco.sgro@unikore.it

Abstract submitted to: Autumn Conferences of Sports Science. Costa Blanca Sports Science Events, 18-19 December 2020. Alicante, Spain.

JOURNAL OF HUMAN SPORT \& EXERCISE ISSN 1988-5202

(c) Faculty of Education. University of Alicante

doi:10.14198/jhse.2021.16.Proc2.59 


\section{INTRODUCTION}

The human body and the human attitude to the physical activity represent the building block of the child's development process and they have a significant role in the growth and maturing of the child. Accordingly, the achievement of autonomy, the construction of personal identity, and the acquisition of skills are important objectives to achieve during childhood and adolescence. In this respect, several studies were primarily focused on assessing the developmental level of fundamental movement skills (Tortella, Haga, Loras, Sigmundsson, \& Fumagalli, 2016; Schembri, Quinto, Aiello, Pignato, \& Sgrò, 2019). At the same time, the physical activity has been recognized as an effective educational tool which operates on several fields, such as motor (proprioception, gestural language, laterality, body control, balance), cognitive (motor and rational memory, spatial-temporal organization of one's body) and social (sense of belonging to one social reality, respect for the other, cooperation) development (Greco, Cataldi, \& Fischetti, 2019).

Physical education is an opportunity to have fun in a healthy and rewarding way, strengthening interpersonal relationships and personal growth in an educational scenario. It stimulates in each student their social skills to manage failures, represents the opportunity to express themselves, to dominate and control their aggression attitude, to improve self-perception and self-awareness, the sense of social participation, and the gratification of feeling part of a process (Tortella, \& Fumagalli, 2017; Fischetti, Latino, Catalsi, \& Greco, 2020).

PE helps to develop transversal skills to consolidate methodological (i.e., finding solutions, even creative, to solve problems), communicative (i.e., expressing and communicating with body language possessing access codes), and socio-relational (i.e., consciously participating in social life) learning aims. In this regards, physical educators have to be trained to the use of affective teaching approach with the aim to help their student to reach the aforementioned aims (D'Elia, 2019).

Although worldwide it has recognized the relevant role of the PE for the global growth of the children, previous studies have focused their designs to address the effect of PE processes mainly on the development of technical proficiency, tactical skills or the health-related benefit of the physical activity (Motl, Dishman, Saunders, Dowda, Felton, \& Pate, 2001; Mullen, et al., 2011). On the contrary, these learning processes could have also a significant effect in the affective domain of learning too.

In sport and physical activities, enjoyment can be described as a positive affective response to the experience which gives pleasure, liking, and fun (Scanlan \& Simons, 1992), also when new technologies have been proposed for developing fundamental movement skills (Sgrò \& Lipoma, 2015). Supaporn \& Griffin, (1998) have highlighted that the enjoyment is one of the main objectives related to PE. Furthermore, pleasure of practice regular physical and recreational activities resulted for young people, adults, and the elderly as a keystone to establish a be active-based behaviour (Frederick, Morrison, \& Manning, 1996; Hashim, Grove, \& Whipp, 2008).

In the last decade, several studies have been carried out for addressing the use of the Tactical Games Model as an alternative pedagogical model to the technical-oriented learning process for targeting learning aims related to all the connected learning domains (Harvey e Jarrett, 2014). Recently, a study have investigated the effects of using the TGM approach in primary school. Anyway, the results related to the assessment of the level of enjoyment were not statistically significant (Coppola, Pignato, Sgrò, \&Lipoma, 2020) . Other similar studies have been conducted by sampling high school students, with results that show how the gameoriented approach represents an appropriate strategy for the enhancement of aspects related to the sociorelational dimension of learning (Sgrò, Barca, Schembri, \& Lipoma, 2020). 
Therefore, because new studies are required in the extent to which it is mandatory address alternative pedagogical-approaches for teaching PE in primary school, the current study provides evidence about the effects on the level of enjoyment during handball-based lessons in 7-years old children. Specifically, we hypothesized that the level of enjoyment increases throughout the game-based lessons.

\section{METHODS}

\section{Design}

A quasi-experimental pre and post-intervention design, with non-equivalent control group, was used in this study. Because the application context was the school, the non-equivalent groups depended by the choice to maintain intact class group throughout the study with the aim to provide an ecological research environment (Harvey \& Jarrett, 2014).

\section{Participants and procedures}

The second-grade classes of a primary school in the south of Italy were selected to participate in this study. Two of the four classes were randomly assigned to the experimental intervention (experimental group - TGM) while the others continued their regular PE curriculum (control group - CG). Overall, sixty-three children were involved in this project: 35 children (19 male, 16 female, mean age: 6.91 years old) were in the TGM, while 29 children (14 male, 15 female, mean age: 6.87 years old) were in the CG. The study was long four months and each group followed a micro educational cycle of eight lessons each one. At the end of the first and the last lesson of these cycles, the children' level of enjoyment was assessed by means of a specific scale. Lesson and assessments were carried out in the gym of the school and they were performed under the control of the PE teacher. Only the students who attended the $85 \%$ of the proposed PE plan and participated in both the assessment sessions were included in the analysis. These limitations were imposed for improving the ecological validity of the study. Each child provided formed consent with the signature of his/her parents or legal guardian to participate in this study prior to it started. The Board of the School and the Ethical Committee of the University of Enna approved the aim of this study and the research methodology here proposed.

\section{PE interventions}

The PE teacher at the school carried out the lesson of both groups (i.e., TGM and CG). The TGM-based cycle was designed by the PE teacher and two PE experts after they followed a specific training on this approach for six weeks (i.e., the training lasted 36 hours). Two experts (i.e., master's degree in PE, two year of expertise in developing game-centred plan) followed the teacher during the lessons in both groups and they were also supported the teacher during the assessment sessions. An external researcher, with more than three years of expertise in the use of the TGM approach, revised positively the plan designed by the teacher and the experts.

The TGM followed eight lessons focused on the following tactical problems related to the handball: ball possession and attack to the goal. Each lesson was designed by following the TGM workflow: Game 1 Questioning - Task-based exercise - Game 2. Game 1 and Game 2 were used to reinforce the motion and the tactics required to solve the problem addressed in each lesson. Questioning was used to improve the tactical awareness. Task-based exercise was designed for improving the technical skills linked to the tactical problem of the lesson. During the games' phases participants were grouped in teams with three or four players each one and they played according to the small-sided games methodology used in similar studies (Sgrò, et al., 2020). The pedagogical principles used for designing these lessons were the cooperative learning and the guided discovery, meanwhile the teaching style was student-centred. 
The CG were involved in a cycle based on lessons developed according to the normal approach used by the PE teacher. The lesson started with a low-to-moderate intensity warm-up, followed by several exercises which addressed the skills required for playing handball (e.g., throw, catch). A final game, played in the regular court with each team composed by six or seven players, was occasionally proposed for closing the lesson. The teaching style used in these lessons was teacher-centred and the pedagogical principles was practice/task.

\section{Enjoyment's measure}

The level of enjoyment was measured by means of the Physical Activity Enjoyment Scale (PACES) developed by Kendzierski and DeCarlo (1991), and validated for Italian language by Carraro, Young, and Robazza (2008). This scale was properly developed for assessing the effect of PE lessons on this aspect of the affective domain of learning. The scale was composed by 16 items which identified a positive scale $(n=9)$ and a negative scale $(n=7)$. Students responded to each question by means of a five-point Likert scale where the value 1 represent "strongly disagree" and the value 5 represent the "strongly agree" answer, respectively. For each student, the value of positive and negative scales were estimated by summing the scores of each item belonged to the respective scale. Validity and reliability of this scale for Italian children and adolescence beyond differences of gender and age were verified in a previous study (Carraro et al., 2008).

\section{Data analysis}

Data were preliminary screened to examine whether they belonged to children who did not respect the limitations related to the participation on the lessons and on the assessment sessions. Furthermore, data were screened to verify the accuracy. Cases with missing data or containing out-of-scale values were deleted. Then, normality was verified by means of the analysis of kurtosis and skewness values. Because these values did not reveal significant deviation from the normality curve, parametric statistics were used. Internal consistency was verified for each scale and assessment time by means of the Cronbach's alpha and it was interpreted as acceptable if it reached or overcome the cut-off value of 0.70 identified by Nunnally (1978). The analysis of item-rest correlation and mean value for each item and scale were also provided for better understand the students' emotional responses. Finally, independent t-test were performed for pre- and postintervention assessments to estimate the effect of the proposed educational plans. The effect size of significant differences was quantified by means of Cohen's $d$ measure and it was estimated according to the following thresholds: 0.20 small; 0.50 moderate; and 0.80 large (Cohen, 2013). Moreover, the $95 \%$ confidence interval for this measure was also estimated for better understanding the effect on the different measures. All the provided analyses were performed by means of JASP (JASP 0.14) and the significance value was set 05 .

\section{RESULTS}

Preliminary analysis revealed that eight children from the CG and six children from the TGM did not meet the limitations criteria imposed for improving the ecological validity of the study, since the relative data was deleted. Because no accuracy problems were revealed, all the other data were used for further analysis. Internal consistency results are showed in Table 1.

About GC positive-ranked answers in pre-intervention analysis, the item "my body feels very good" resulted with the highest item-rest correlation (.86) while the item "I made me feel good" resulted with the highest mean (3.33 \pm 1.35$)$; the item "I get something" resulted with the lowest item-rest correlation (.41) and mean value $(2.71 \pm 1.18)$. In the post-intervention analysis, the item "I found it really nice" resulted with the highest item-rest correlation (.84) and the highest mean value ( $3.48 \pm 1.67)$, while the item "I get something" resulted 
with the lowest item-rest correlation (.11) and mean value $(2.67 \pm 1.23)$. For what concern the negative items, in pre-intervention analysis the item "I don't like" resulted with the highest mean value $(3.19 \pm 1.21)$ while the answer "I feel sad" resulted with the lowest mean value $(2.28 \pm 1.19)$. The lowest item-rest correlation resulted for "I am bored" (.15). In the post-intervention analysis, the item "I don't like" resulted with the highest mean value $(2.71 \pm 1.30)$, while the item "I am bored" resulted with the highest item-rest correlation (.84).

Table 1. Internal consistency analysis for the positive and negative scales.

\begin{tabular}{lcccc}
\hline Group & Scale & Test & Cronbach's $\boldsymbol{\alpha}$ & 95\% Cl Cronbach's $\boldsymbol{\alpha}$ \\
\hline \multirow{4}{*}{ CG $[\mathrm{n}=21]$} & Positive & Pre & 0.92 & $0.86,0.96$ \\
& Negative & Pre & 0.81 & $0.64,0.91$ \\
& Positive & Post & 0.93 & $0.87,0.96$ \\
& Negative & Post & 0.90 & $0.80,0.95$ \\
\hline \multirow{4}{*}{ TGM $[\mathrm{n}=30]$} & Positive & Pre & 0.92 & $0.87,0.96$ \\
& Negative & Pre & 0.82 & $0.70,0.90$ \\
& Positive & Post & 0.82 & $0.71,0.90$ \\
& Negative & Post & 0.20 & $0.18,0.28$ \\
\hline
\end{tabular}

About TGM positive-ranked answers in pre-intervention analysis, the item "I enjoyed" resulted with the highest item-rest correlation (.84) and mean value (3.57 \pm 1.50$)$, while the item "I get something" " resulted with the lowest item-retest correlation (.39) and mean value (2.70 \pm 1.64$)$. In the post-intervention analysis, the item "It is very exciting" resulted with the highest item-rest correlation (.69), while the item "I enjoyed" resulted with the highest mean value $(4.83 \pm 0.38)$, but whit the lowest item-rest correlation (.21). For what concern the negative items, the answer "I don't like it" resulted with the highest mean value (3.00 \pm 1.41$)$, while the answer "I feel sad" resulted with the lowest mean value $(2.16 \pm 1.26)$. The lowest item-rest correlation value resulted for the item "It is disappointing" (.37). For what concern the negative items analysis of post-intervention, the Cronbach's value is lower than the cut-off point identified by Nunnaly, since this scale was ranked as not reliable.

Figure 1 show the comparison between the scores of the positive and negative scales of each group, distinctly for the pre- and post-intervention assessment.
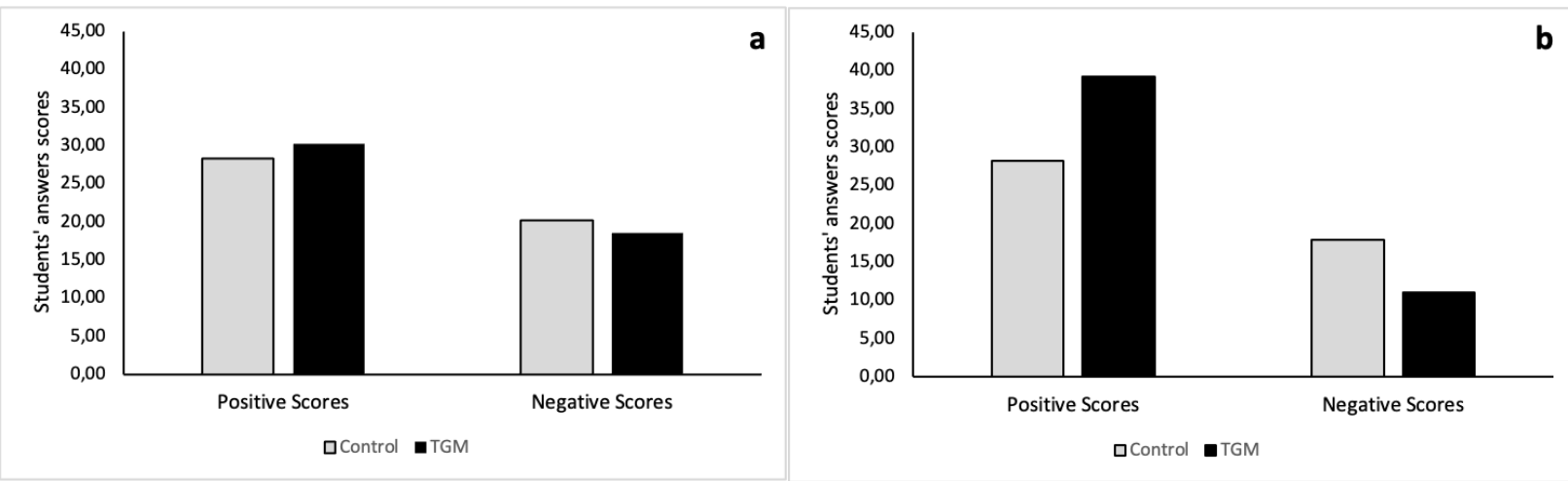

Figure 1. a) Paces-IT scores acquired pre-intervention. b) Paces-IT scores acquired post-intervention.

Comparisons in pre-intervention assessment did not reveal any significant difference neither for positive than negative scores. In post-intervention comparisons, significant differences were found for the positive scores 
$(t=5.16, d f=49, p<.0001$, Cohen's $d=1.47,95 \% \mathrm{Cl}$ Cohen's $d=0.83,2.09)$ and for the negative scores $(t$ $=5.55, d f=49, p<.0001$, Cohen's $d=1.58,95 \%$ Cl Cohen's $d=0.93,2.21$ ).

\section{DISCUSSION AND CONCLUSION}

The purpose of this study was to examine the effects of two teaching approaches on the level of enjoyment during PE lessons in primary school. Students were grouped into two different groups (i.e., CG and TGM) at the start of the study. The CG followed the regular physical education lessons according to national guidelines. The TGM followed lessons designed according to the Tactical Games Model. The lessons of both groups were carried out by the same teacher. After the first lessons, and at the end of the last lessons, in agreement with the approaches provided in similar studies (Coppola, et al., 2020; Sgrò, et al., 2020; Harveson, Hannon, Brusseau, Podlog, McMullen, \& England, 2016), the students' level of enjoyment was acquired by means of the Italian version of the PACES scale. The effect of these teaching plans was interpreted according to the Cohen's effect size measure.

The differences between-groups at the end of the proposed plans were clear and with statistical significance. In detail, the students of the TGM showed an improvement in their level of enjoyment at the end of their plan, therefore the current hypothesis was verified. These results are in agreement with several previous studies (Harvey and Jarret, 2014; Sgrò, et al., 2020). At the same time, the current results were different from the ones provided by Coppola and colleagues (2020) in a similar design (i.e., children with similar age who followed a TGM intervention built by using hands-based games). Anyway, we hypothesized that the differences can be explained by considering the game chosen for implementing the educational plan. Specifically, here we proposed an invasion game (i.e., handball) which have been suggested as the most adequate to start a new process based on the use of this teaching method (Mitchell, Oslin, \& Griffin, 2020).

About the results of internal consistency analysis of the scale, two aspects were of interest and one resulted as a withdraw. The item 10 , which belonged to the positive scale, resulted with the lowest item-rest correlation for each group in pre- and post-intervention assessment. A possible explanation for these results was identified in the cognitive development at this age. Specifically, previous studies identified that from 6 to 12 years old is an important developmental time in which children develop complex cognitive skills such as the ability to use personal experiences to make decisions and to rely on mental cues to understand emotions (Stone \& Lemanek, 1990; Tortella \& Fumagalli, 2017). Accordingly, we hypothesized that the current answers were not link to a positive aspect because children waited for a material reward at the end of their lesson. For what concern the second point of interest, we have verified a high level of item-rest correlation for the item "I enjoyed" in the children who belonged to the TGM. In this respect, fun is considered one of the most important reasons for children and adolescents involved in physical activity, and a lack of fun is likely to lead them to withdraw (Supaporn \& Griffin, 1998). Because this item also resulted with the highest mean score in the post-intervention answers of the TGM, we can support the idea that the use of the TGM provided fun and challenging teaching-learning processes.

The main limits of this study were the low size of the sample and the low level of internal consistency in the post-intervention assessment. Therefore, future studies will be proposed to overcome these limits and to address other enjoyment-related aspects. Specifically, in addition to the PACES it would be useful to use other scales, such as the Questionnaire for the Assessment of Enjoyment in Physical Education (QUAEPE), in order to enrich the information needed to measure levels of enjoyment. Furthermore, it may be of interest to study whether the level of fun in PE can be linked with the general academic performance of students in other disciplines, as suggested by Lohbeck and colleagues (2019). 


\section{CONCLUSION}

The current study somewhat extent the current literature by providing new evidence about the effects related to the use of a TGM-based approach for supporting adequate and fun-based PE lessons in primary school. In this respect, the use of the PACES within PE lesson can help physical educators to understand if their teaching method is valid or needs some changes in order to avoid low level of academic progression and to limit students dropout from physical and sports activities.

\section{AUTHOR CONTRIBUTIONS}

R.S.: Conceptualization, Methodology, Data curation, Writing-Review \& Editing, and Supervision. R.C.: Conceptualization, Investigation, Formal Analysis, Writing-Original Draft Preparation. P.T.: Methodology, Formal Analysis, Writing-Original Draft Preparation. F.S.: Methodology, Data curation, Writing-Review \& Editing, and Supervision. All authors have read and agreed to the published version of the manuscript.

\section{ACKNOWLEDGEMENTS}

The authors would like to thank Prof. Rosa Cartella, head of the school "M.L. King" of Caltanissetta, for their support during this study.

\section{REFERENCES}

Carraro, A., Young, M. C., \& Robazza, C. (2008). A contribution to the validation of the physical activity enjoyment scale in an Italian sample. Social Behavior and Personality: an international journal, 36(7), 911-918. https://doi.org/10.2224/sbp.2008.36.7.911

Cohen, J. (2013). Statistical power analysis for the behavioral sciences. Academic press. https://doi.org/10.4324/9780203771587

Coppola, R., Pignato, S., Sgrò, F., \& Lipoma, M. (2020). Effects of two different physical education teaching approaches on the levels of enjoyment in the Italian primary school students. Journal of Human Sport and Exercises, 15(4), S1251-S1261. https://doi.org/10.14198/ihse.2020.15.Proc4.26

D'Elia, F. (2019)The training of physical education teacher in primary school. Journal of Human Sport and Exercise, 14, pp. S100-S104. https://doi.org/10.14198//hse.2019.14.Proc1.12

Fischetti, F., Latino, F., Cataldi, S., Greco, G. (2020). Gender differences in body image dissatisfaction: The role of physical education and sport. Journal of Human Sport and Exercise, 15 (2), pp. 241-250. https://doi.org/10.14198/ihse.2020.152.01

Frederick, C. M., Morrison, C., \& Manning, T. (1996). Motivation to participate, exercise affect, and outcome behaviors toward physical activity. Perceptual and Motor Skills, 82(2), 691-701. https://doi.org/10.2466/pms.1996.82.2.691

Greco, G., Cataldi, S., Fischetti, F. (2019) . Effectiveness of a short after-school intervention on physical fitness in school-aged children extracurricular multilateral training improves physical fitness in children, Ricerche di Pedagogia e Didattica, 14 (1), pp. 143-164.

Harvey, S., \& Jarrett, K. (2014). A review of the game-centred approaches to teaching and coaching literature since 2006. Physical Education and Sport Pedagogy, 19(3), 278-300. https://doi.org/10.1080/17408989.2012.754005

Harveson, A. T., Hannon, J. C., Brusseau, T. A., Podlog, L., McMullen, B., \& England, A. (2016). Acute Exercise and Academic Achievement in Elementary School Youth. Research Quarterly for Exercise and Sport, 87(S2), A75. 
Hashim, H., Grove, R. J., \& Whipp, P. (2008). Validating the youth sport enjoyment construct in high school physical education. Research Quarterly for Exercise and Sport, 79(2), 183-194. https://doi.org/10.1080/02701367.2008.10599482

Kendzierski, D., \& DeCarlo, K. J. (1991). Physical activity enjoyment scale: Two validation studies. Journal of sport \& exercise psychology, 13(1), 50-64. https://doi.org/10.1123/isep.13.1.50

Lohbeck, A., Engels, E. S., \& Freund, P. A. (2019). Assessing students' enjoyment in physical education: measurement invariance across school tracks and relationships with grades. Journal of Psychoeducational Assessment, 37(8), 1023-1029. https://doi.org/10.1177/0734282918804600

Mitchell, S., Mitchell, S. A., Oslin, J., \& Griffin, L. L. (2020). Teaching sport concepts and skills: A tactical games approach. Human Kinetics Publishers.

Motl, R. W., Dishman, R. K., Saunders, R., Dowda, M., Felton, G., \& Pate, R. R. (2001). Measuring enjoyment of physical activity in adolescent girls. American journal of preventive medicine, 21(2), 110-117. https://doi.org/10.1016/S0749-3797(01)00326-9

Mullen, S. P., Olson, E. A., Phillips, S. M., Szabo, A. N., Wójcicki, T. R., Mailey, E. L., \& McAuley, E. (2011). Measuring enjoyment of physical activity in older adults: invariance of the physical activity enjoyment scale (paces) across groups and time. International Journal of Behavioral Nutrition and Physical Activity, 8(1), 103. https://doi.org/10.1186/1479-5868-8-103

Scanlan, T. K., Simons, J. P. (1992). The construct of sport enjoyment. In G. C. Roberts (Ed.), Motivation in sport and exercise (pp. 202-203). Champaign, IL: Human Kinetics.

Schembri, R., Quinto, A., Aiello, F., Pignato, S., \& Sgrò, F. (2019). The relationship between the practice of physical activity and sport and the level of motor competence in primary school children. Journal of Physical Education and Sport, 19 (Suppl. Issue 5), 1994-1998.

Sgrò, F., Barca, M., Schembri, R., \& Lipoma, M. (2020). Assessing the effect of different teaching strategies on students' affective learning outcomes during volleyball lessons. Journal of Physical Education and Sport, 20, 2136-2142.

Sgrò, F., \& Lipoma, M. (2015). Can An Exergames Training Program Improve The Jump For Height Skill In Childhood. Turkish Online Journal of Educational Technology, Special Issue for INTE 2015, 8996.

Stone, W. L., \& Lemanek, K. L. (1990). Developmental issues in children's self-reports. In A. M. La Greca, Through the eyes of the child: Obtaining self-reports from children and adolescents (p. 18-56). Allyn \& Bacon.

Supaporn, S., \& Griffin, L. L. (1998). Undergraduate students report their meaning and experiences of having fun in physical education. Physical Educator, 55(2), 57-70.

Tortella, P., \& Fumagalli, G. (2017). The effect of teaching methodologies in promoting physical and cognitive development in children. Physical Activity and Educational Achievement: Insights from Exercise Neuroscience, 297. https://doi.org/10.4324/9781315305790-17

Tortella, P., Haga, M., Loras, H., Sigmundsson, H., \& Fumagalli, G. (2016). Motor skill development in Italian pre-school children induced by structured activities in a specific playground. PLoS One, 11(7), e0160244. https://doi.org/10.1371/journal.pone.0160244

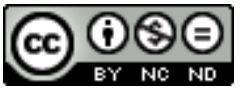

This work is licensed under a Attribution-NonCommercial-NoDerivatives 4.0 International (CC BY-NC-ND 4.0). 